\title{
Late Pregnancy Loss
}

National Cancer Institute

\section{Source}

National Cancer Institute. Late Pregnancy Loss. NCI Thesaurus. Code C120260.

The loss of a pregnancy between 13 and 22 weeks. 